\title{
Anti-malaria drug mefloquine induces motor learning deficits in humans
}

\author{
Thomas A. van Essen ${ }^{1 *}$, Ruben S. van der Giessen ${ }^{1}$, Sebastiaan K. E. Koekkoek', Frans VanderWerf', Chris I. De \\ Zeeuw' ${ }^{1}$ Perry J. J. van Genderen ${ }^{2}$, David Overbosch ${ }^{2}$ and MarcelT. G. de Jeu ${ }^{1 *}$
}

' Department of Neuroscience, Erasmus Medical Center, Rotterdam, Netherlands

2 Travel Clinic, Havenziekenhuis and Institute for Tropical Diseases, Rotterdam, Netherlands

Edited by:

lan M. Stanford, Aston University, UK

\section{Reviewed by:}

Carol Holland, Aston University, UK

Stephen D. Hall, Aston University, UK

*Correspondence:

Thomas A. van Essen and Marcel T. G. de Jeu, Department of Neuroscience, Erasmus Medical Center, Dr. Molewaterplein 50, 3015 GE

Rotterdam, Netherlands.

e-mail: t.vanessen@erasmusmc.nl;

m.dejeu@erasmusmc.nl
Mefloquine (a marketed anti-malaria drug) prophylaxis has a high risk of causing adverse events. Interestingly, animal studies have shown that mefloquine imposes a major deficit in motor learning skills by affecting the connexin 36 gap junctions of the inferior olive. We were therefore interested in assessing whether mefloquine might induce similar effects in humans. The main aim of this study was to investigate the effect of mefloquine on olivary-related motor performance and motor learning tasks in humans. We subjected nine participants to voluntary motor timing (dart throwing task), perceptual timing (rhythm perceptual task) and reflex timing tasks (eyeblink task) before and $24 \mathrm{~h}$ after the intake of mefloquine. The influence of mefloquine on motor learning was assessed by subjecting participants with and without mefloquine intake (controls: $n=11$ vs mefloquine: $n=8$ ) to an eye-blink conditioning task. Voluntary motor performance, perceptual timing, and reflex blinking were not affected by mefloquine use. However, the influence of mefloquine on motor learning was substantial; both learning speed as well as learning capacity was impaired by mefloquine use. Our data suggest that mefloquine disturbs motor learning skills. This adverse effect can have clinical as well as social clinical implications for mefloquine users. Therefore, this side-effect of mefloquine should be further investigated and recognized by clinicians.

Keywords: mefloquine, gap junctions, motor behavior, eye-blink conditioning, cerebellum

\section{INTRODUCTION}

The quinolone derivative mefloquine is widely used in the treatment and prophylaxis of malaria in travelers to areas with chloroquine-resistant falciparum malaria (Palmer et al., 1993). In the Netherlands mefloquine is generally prescribed when traveling for longer than 6 weeks to a malaria endemic region. Mefloquine has gained popularity due to its weekly dosing regime and is used worldwide by all kinds of civil and military organizations.

A negative effect of mefloquine is that it occasionally causes neuropsychiatric adverse events. A number of studies on mefloquine tolerability in young and healthy populations have shown that mild neuropsychiatric adverse events, like headache, strange or vivid dreams, dizziness, anxiety, and sleeplessness, may occur in up to $32 \%$ of mefloquine users (Schlagenhauf et al., 1996, 2003; van Riemsdijk et al., 2002), while more severe neuropsychiatric adverse events, like psychosis and bipolar disorder, have also been described (Croft and World, 1996; Piening and Young, 1996; Even et al., 2001; Toovey, 2009).

Although, it is known that mefloquine interacts with an array of protein targets and cellular signaling pathways no studies have been performed regarding the nature of the origin of these adverse events (Lim and Go, 1985; Gribble et al., 2000; Maertens et al., 2000; Kang et al., 2001; Dow et al., 2003; Weiss et al., 2003; Cruikshank et al., 2004). Mefloquine has been shown to block connexin 36 (Cx36) gap junction very potently (Cruikshank et al., 2004; Margineanu and Klitgaard, 2006). Cx36 is a plasma membrane protein responsible for the formation of gap junctions between neurons (Condorelli et al., 1998; Sohl et al., 2005) and has been found in many brain areas such as thalamus, hippocampus, basal ganglia, cerebral cortex, olfactory bulb, brainstem, and retina (Condorelli et al., 2000). Cx36 is highly expressed in the gap junctions of the inferior olive (IO) and these electrical synapses are the main source of intra-olivary electrical transmissions (De Zeeuw et al., 1995; Condorelli et al., 2000). The IO gives rise to the climbing fibers projecting to the Purkinje cells in the cerebellar cortex and functionally integrates sensory information and motor output resulting in well coordinated motor performance, motor learning, and cognitive processes (Simpson et al., 1996; Strick et al., 2009).

In mice that were injected with mefloquine in their IO, timing deficits of newly learned motor responses were found in an associative motor learning task (Van Der Giessen et al., 2008), indicating the importance of Cx36 gap junctions in the process of learningdependent timing. Other studies revealed that the $\mathrm{IO}$ is involved in the cognitive property of perception of temporal complex rhythmic stimuli (Xu et al., 2006; Liu et al., 2008; Wu et al., 2010). The impact of mefloquine on the IO and on the olivocerebellar dependent behaviors has never been investigated in humans. Results from animal studies and the high prevalence of mefloquine associated neuropsychiatric adverse events led us to study the hypothesis that mefloquine alters olivocerebellar related behaviors in humans.

Therefore, we have investigated the effect of mefloquine on different aspects of motor performance, perceptual timing, and motor learning in humans. We examined the influence of mefloquine by studying voluntary motor timing (dart throwing task: Smeets et al., 
2002), perceptual timing (rhythm perception task: Xu et al., 2006), reflex timing (reflex blinking: Koekkoek et al., 2002; Smit et al., 2008), and an associative motor learning task (eye-blink conditioning: Koekkoek et al., 2002; Smit et al., 2008).

\section{MATERIALS AND METHODS STUDY POPULATION AND EXPERIMENTAL SET UP}

We recruited volunteers, who were prescribed mefloquine (Roche, USA; the commercial name marketed as Lariam ${ }^{\circledR}$ ) for malaria prophylaxis at the Travel Clinic Havenziekenhuis in Rotterdam, the Netherlands. Written informed consent was obtained from the participants or the parents of the participants when they were younger than 18 years. The experimental protocol was approved by the Erasmus MC Medical Ethics Committee (MEC-2004-205).

Participants who had used mefloquine in the preceding 2 months, who had risk factors for concentration impairment (e.g., use of opioids, hypnotics or tranquilizers during the study period or use of alcohol $4 \mathrm{~h}$ before testing) or who had illnesses resulting in altered motor behavior were excluded from this study. From the participants information was collected on gender, weight, height, age, weekly physical exercise, and previous mefloquine intake by use of a questionnaire (Table 1). The participants were requested to take the standard dose of $250 \mathrm{mg}$ mefloquine at the end of dinner, as food facilitates mefloquine absorption (Crevoisier et al., 1997). One day after the first mefloquine intake, users were carefully reviewed for adverse effects (by Thomas A. van Essen, see also Table 1).

The experimental set up consisted of performance tasks: (a) dart throwing task, (b) perceptual timing task, and (c) reflex blinking task. To test motor learning, the eye-blink conditioning task was used. The performance experiments were executed 2-4 days prior to the intake of mefloquine (baseline) and $24 \mathrm{~h}$ after the intake of the first mefloquine tablet. The learning experiments were only performed once per (naïve) subject, in order to prevent contamination

Table 1 | Characteristics participants.

\begin{tabular}{llll}
\hline Characteristics & $\begin{array}{l}\text { Performance } \\
\text { task }(\boldsymbol{n}=\mathbf{9})\end{array}$ & $\begin{array}{l}\text { Learning task } \\
\text { (no mefloquine; } \\
\boldsymbol{n}=\mathbf{1 1})\end{array}$ & $\begin{array}{l}\text { Mefloquine } \\
(\boldsymbol{n}=\mathbf{8})\end{array}$ \\
\hline Men/women & $6 / 3$ & $7 / 4$ & $4 / 4$ \\
Age (years) & 40.7 & 24.3 & 25.0 \\
Age range (years) & $17-67^{\mathrm{a}}$ & $20-35^{\mathrm{a}}$ & $17-40^{\mathrm{a}}$ \\
Weight (kg) & 74.2 & 65.5 & 68.8 \\
Physical exercise & $6(67 \%)$ & $7(64 \%)$ & $5(63 \%)$ \\
$\begin{array}{l}\geq 2 \times / \text { week) } \\
\text { Adverse events }\end{array}$ & $3(33 \%)^{\mathrm{b}}$ & - & $3(38 \%)^{\mathrm{b}}$ \\
Insomnia & 2 & & 1 \\
Head ache & 1 & & 1 \\
Abnormal & 1 & & 2 \\
dreams/nightmares & & &
\end{tabular}

Gender, mean age, age range, mean weight, amount of exercise level, and adverse events for each group.

${ }^{a}$ Age range is different between the motor performance and the motor learning participants.

${ }^{b}$ Numbers do not add up to total adverse events since some participants had more than one adverse event. of the results with a memory trace. The eye-blink conditioning task was performed in a group of participants $24 \mathrm{~h}$ after the intake of their first mefloquine tablet and in an age- and sex-matched control group who did not use mefloquine.

\section{PERFORMANCE EXPERIMENTS Dart throwing task}

In this task participants threw 25 darts at a dartboard and were told to aim for the bull's eye while holding their underarm vertically during the course of each throw. They were placed on a standard range from the dart board $(2 \mathrm{~m})$ and each throw was followed by a short pause of $5 \mathrm{~s}$.

Throwing imprecision can be divided in a horizontal and vertical component. The horizontal $\left(\mathrm{E}_{\mathrm{x}}\right)$ and vertical deviations $\left(\mathrm{E}_{\mathrm{y}}\right)$ of each dart from the center of the bull's eye were determined manually (Figure 1B). Under normal conditions, imprecision in release timing or throwing speed is not the main source of throwing imprecision, but the imprecision in direction of motion at the time of release is considered the main cause of throwing imprecision (Smeets et al., 2002). However, when either speed or timing precision is affected by mefloquine, an additional error source is introduced that will affect the precision of the dart throw. This error source will only affect the vertical component, but not the horizontal component, of the throw (Figure 1A). Therefore, we would expect an enhanced variability in the vertical deviation compared to the horizontal deviation after the use of mefloquine. The speed and timing sensitivity of the dart throw was determined by dividing vertical deviation from the target $\left(\mathrm{E}_{\mathrm{y}}\right)$ by the total deviation from the target $\left(\mathrm{E}_{\mathrm{y}}+\mathrm{E}_{\mathrm{x}}\right)$. The precision of the dart throw was determined by dividing the standard deviation of the vertical displacement from the target $\left(\mathrm{sdE}_{\mathrm{y}}\right)$ by the total standard deviation of the displacement from the target $\left(\mathrm{sdE}_{\mathrm{y}}+\mathrm{sdE}_{\mathrm{x}}\right)$.

\section{Rhythm perception task}

Functional MRI studies revealed that the IO is activated during perception of complex rhythms and perception of a single stimulus with unexpected timing, and that the IO is sensitive to the temporal structure of sensory input (Xu et al., 2006; Liu et al., 2008; Wu et al., 2010). In this task participants have to compare successive auditory rhythms (Xu et al., 2006). Two successive rhythms were generated by two pairs of four tones. Each pair consisted of four tones of $500 \mathrm{~Hz}$ with a duration time of $5 \mathrm{~ms}$ and these tones were separated from each other by intervals of $333 \mathrm{~ms}$. The pairs were separated by an interval of $2 \mathrm{~s}$ (Figure 2A). A rhythm asynchrony was introduced in either the first or second four-tone rhythm, consequently the other four-tone rhythm became the designated standard rhythm. Rhythm asynchrony was achieved by shifting the second tone of the rhythm closer to the first (i.e., shortening the inter-tone interval). This shortening of the inter-tone interval (perturbation) varied randomly throughout each test block between $0,10,25,50,75$, and 100 ms. The task consisted of eight blocks and in each block the participants were exposed to all six perturbations. For each perturbation we determined the number of errors that were made per subject. The $0 \mathrm{~ms}$ perturbation served as a control of understanding the task and to asses to what extent the task was subject to guessing. After each series of two rhythms participants were asked whether the rhythms were identical or not. 
A

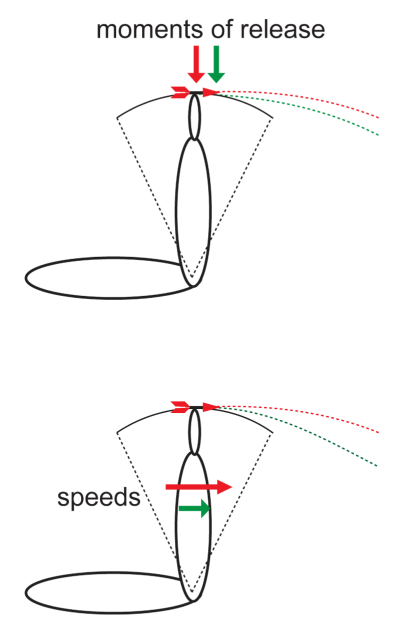

C

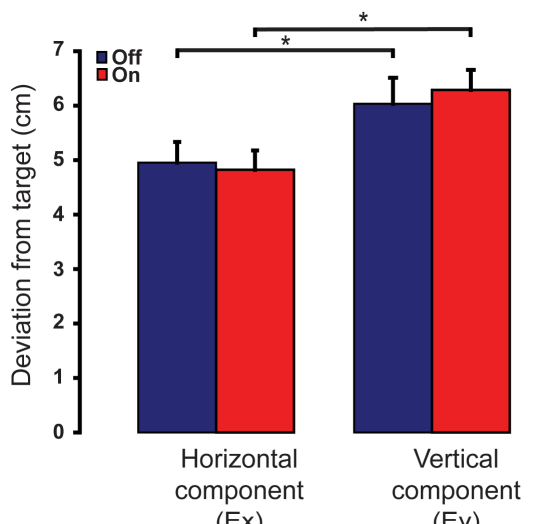

(Ex)

(Ey)
D

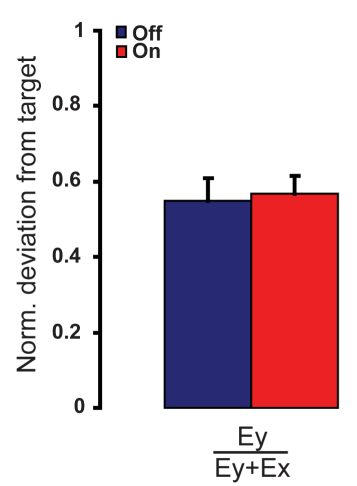

Target

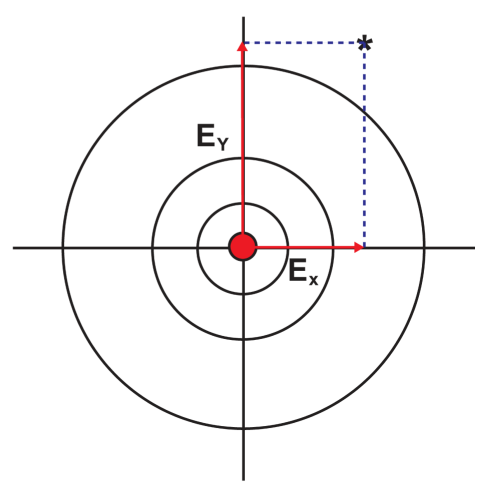

E

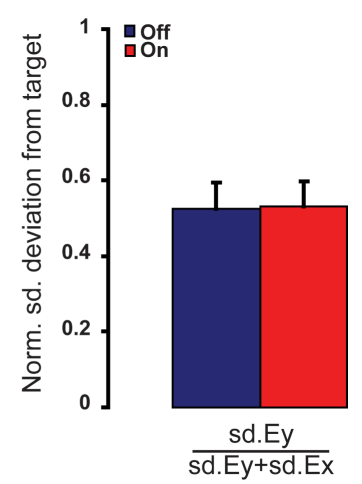

FIGURE 1 | Dart throwing precision is not affected by the intake of mefloquine. (A) Schematic representations of two arms at the time of releasing the dart. Vertical throwing precision is more complex than horizontal throwing precision; it depends more on the moment of release and the speed of the throw. (B) Participants threw darts at a dartboard and for each throw the horizontal $\left(E_{x}\right)$ and vertical deviations $\left(E_{y}\right)$ from the center of the bull's eye were determined. (C) The vertical and horizontal precision were not altered by the intake of mefloquine $(n=9)$. Under both conditions, the horizontal component of the throw is more precise than the vertical component $\left({ }^{*}\right.$ both $p<0.05, n=9, t$ test). (D) The normalized vertical deviation from the target $(n=9)$ and $(\mathbf{E})$ the normalized standard deviation of vertical deviation from the target $(n=9)$ were not affected by the intake of mefloquine. Blue bars indicate mean + SEM (error bar) before mefloquine intake and red bars indicate mean + SEM (error bar) $24 \mathrm{~h}$ after mefloquine intake.
The participants were explicitly instructed not to guess. Due to the involvement of the IO in this task and the temporal structure of the task, we would expect more errors in discriminating the rhythms after the use of mefloquine.

\section{Reflex blinking}

Participants were subjected to reflex blinking and eye-blink conditioning procedures. Eye blinks were recorded with the use of magnetic distance measurement technique as described by (Koekkoek et al., 2002; Smit et al., 2008). Briefly, a magnetoresistive sensor was attached at the rim of the orbit below the right lower eyelid, while a small gold plated neodymium magnet was attached to the tarsal portion of the right upper eyelid (Figure 3A). The signal was amplified by a pre-amplifier close to the sensor and further amplification could be adjusted per subject. The signal was digitized $(1000 \mathrm{~Hz})$ using National Instruments hardware. A custom made LabView (National Instruments, Austin, TX, USA) script controlled the monitoring of eyelid movement, presentation of the stimuli and capturing of data on disk. Via the puff nozzle, an air puff (unconditioned stimulus: US) was directed to the cornea close to the outer canthus of the eye at a distance of about $15 \mathrm{~mm}$. The apparatus served to deliver a 20-ms air-puff with an intensity of $10-50$ PSI at the source. The intensity and duration were manually adjusted to elicit a single blink reflex (unconditioned response: UR). 


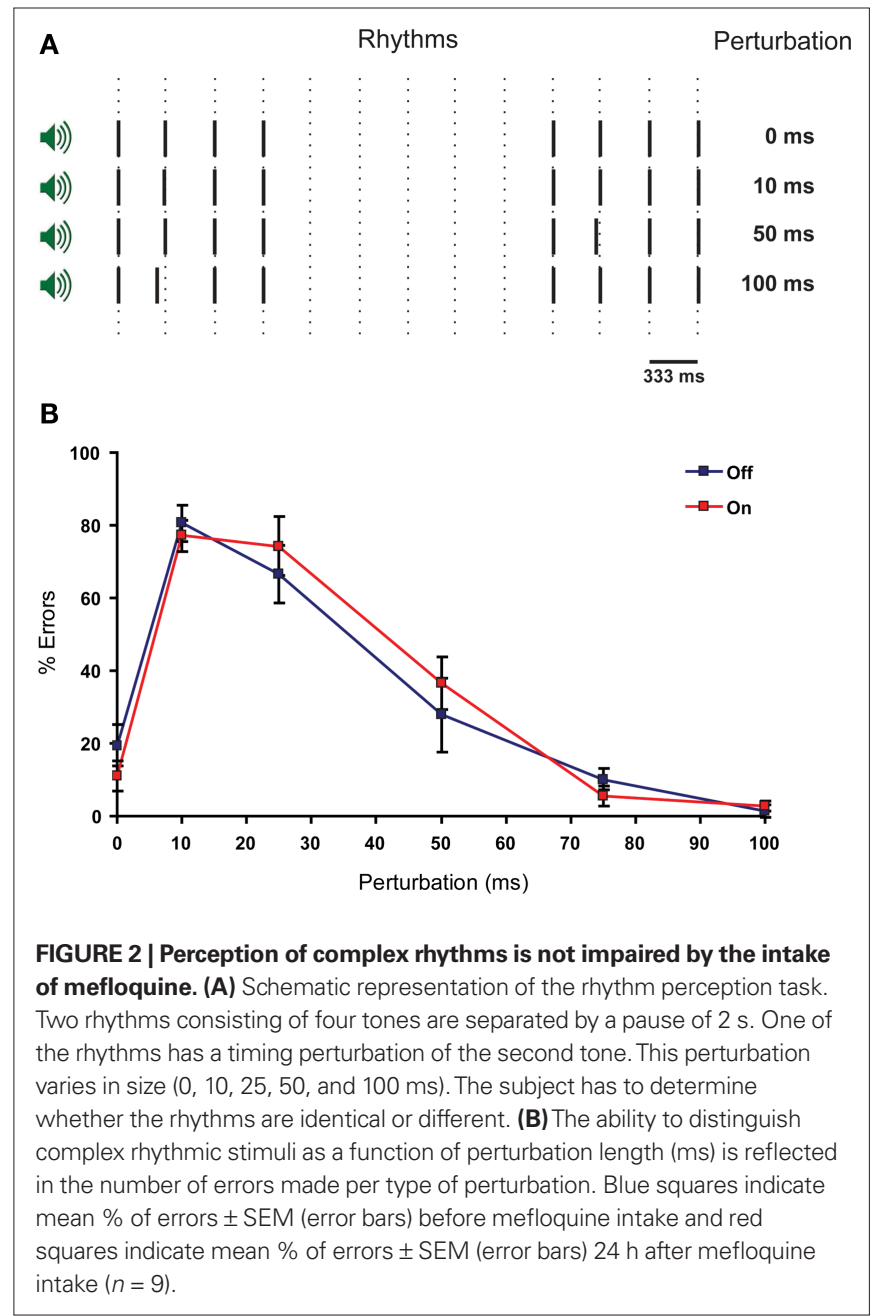

In the reflex blinking sessions 15 blinks were randomly evoked in $1 \mathrm{~s}$ trials each. For each reflex blink three temporal aspects, the onset, peak time velocity, and peak time amplitude were determined. The onset of the blink is the time between the start of the US and the start of the eyelid movement, the peak time velocity is the time between the start of the US and the moment that the eyelid reaches the maximal velocity (which is determined after differentiating the eyelid trace), and the peak time amplitude is the time between the start of the US and the moment that the eyelid reaches the maximal amplitude (Figure 3A).

\section{MOTOR LEARNING: EYE-BLINK CONDITIONING}

Eye-blink conditioning is an associative learning task (Gormezano et al., 1962), in which a reflex blink (induced by US) is associated to a tone (conditioned stimulus: CS). Repetitive paired presentation of the CS with the US results in the generation of a conditioned response (CR), a closure of the eyelid upon presentation of CS (Figure 4A). The olivocerebellar system is involved in this conditioning of the eyelid response (Medina et al., 2000).

For this task the participants were equipped with a headphone, video goggles (Logitech, USA), and a puff nozzle. The headphone and video goggles provided additional entertainment in order to

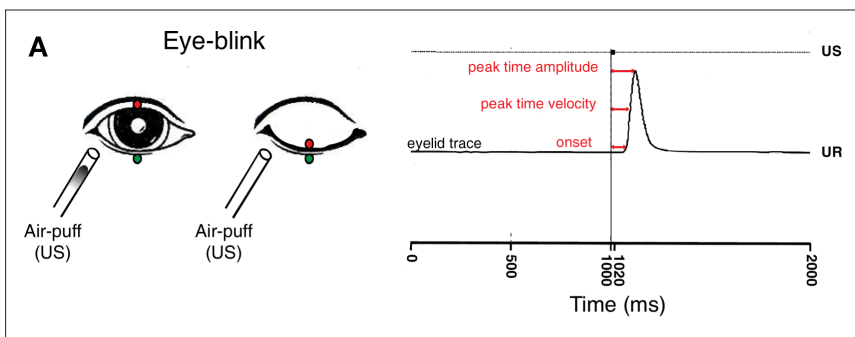

B

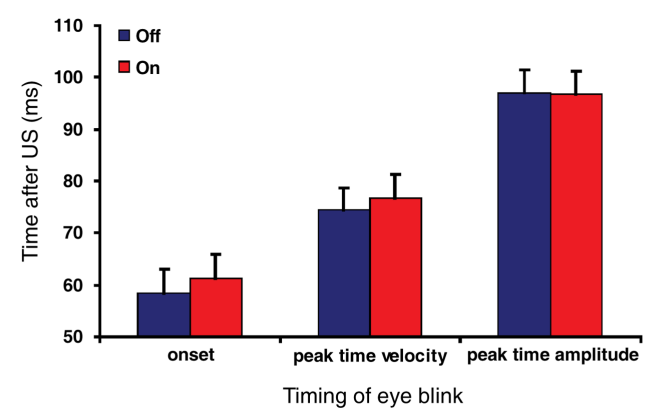

C

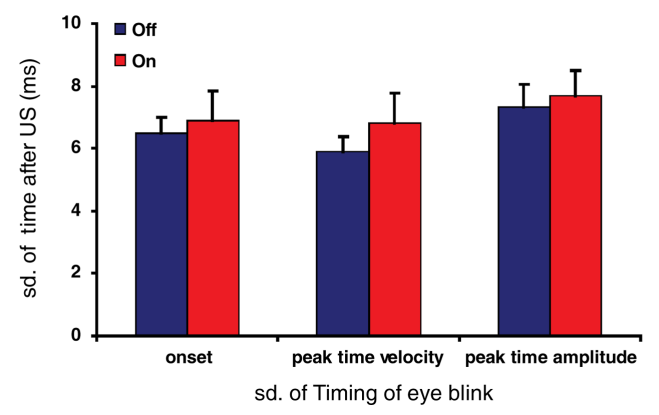

FIGURE 3 | Reflex blinking is not affected by the intake of mefloquine. (A) Left panel: Schematic drawing of eye-blink recording system. A gold plated neodymium magnet was attached to the edge of the upper eyelid (red circle), while a magnetoresistive sensor was attached at the edge of the orbit below the right lower eyelid (green circle). A blink was induced by a small air-puff (unconditioned stimulus: US). An increased magnetic force is detected by the sensor during closure of the eyelid. Right panel: eyelid movement recording of an unconditioned response (UR). Three temporal aspects of the reflex blink were determined: the onset, peak time velocity and peak time amplitude (red arrows). Figure is adopted from Smit et al. (2008). (B) Histogram of eye-blink timing parameters before (blue bars) and $24 \mathrm{~h}$ after the intake of mefloquine (red bars). (C) Histogram of standard deviations of the measured eye-blink timing parameters before (blue bars) and $24 \mathrm{~h}$ after the intake of mefloquine (red bars). Histograms show mean and SEM $(n=9)$.

ensure that attention deficits and anxiety would not interfere with the eye-blink conditioning session (Smit et al., 2008). In the eyeblink conditioning sessions, participants received eight blocks of eight 2 s trials. Each block consisted of one air-puff only trial (US only) as described above, one trial in which the tone (CS) was presented alone (CS only) and six trials in which tone and airpuff were paired. In these paired trials the $20 \mathrm{~ms}$ air-puff ended simultaneously with the $520 \mathrm{~ms}$ tone by presenting it with a $500 \mathrm{~ms}$ delay after onset of the tone (Figure 4A). For each CS only and paired trial the presence or absence of a CR was determined. For each subject and experiment we calculated the percentage of CRs 


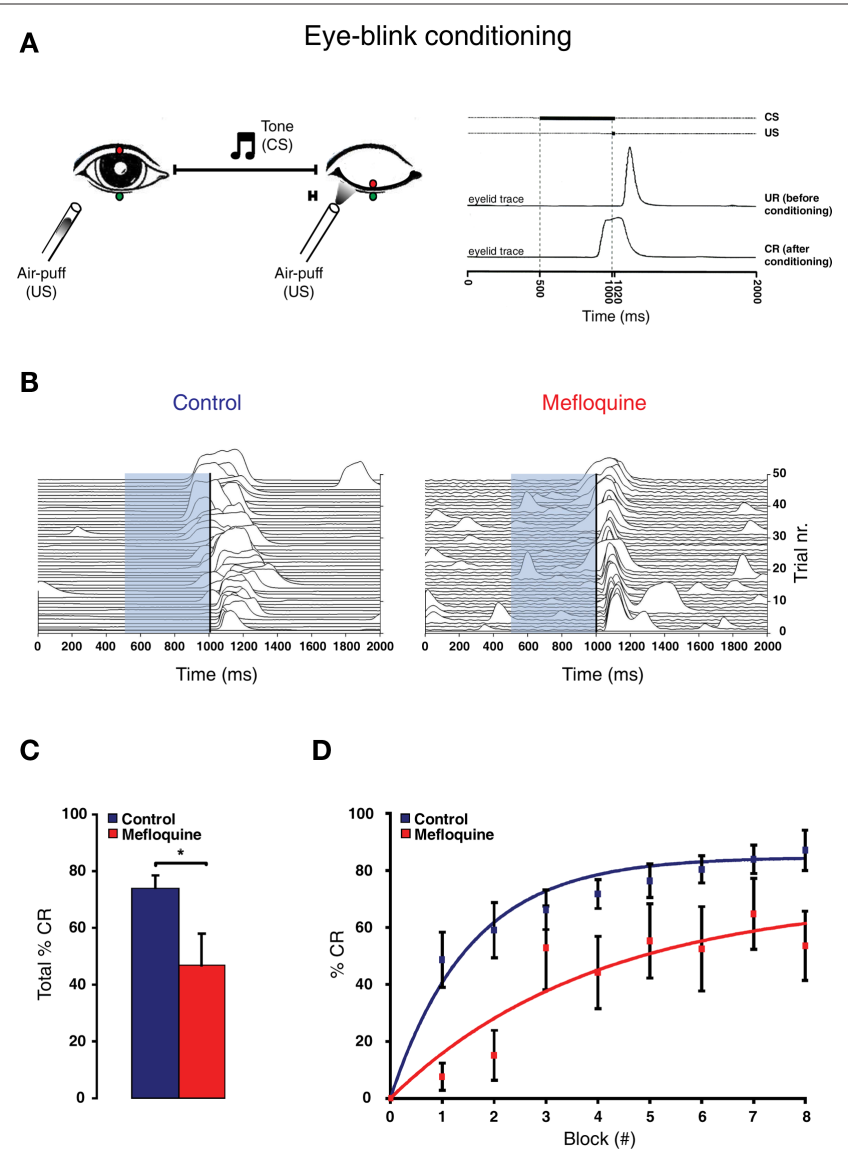

FIGURE 4 | Eye-blink conditioning is impaired by the intake of mefloquine. (A) Left panel: Schematic drawing of eye-blink conditioning. Right panel: eyelid movement recording of a response before (UR: unconditioned response) and after conditioning (CR: conditioned response). (B) Example of 48 eyelid recordings of a control subject (i.e., no mefloquine use; left panel) and a mefloquine user (right panel) during the acquisition. The conditioned stimulus (CS) is indicated by the light-blue bar, ranging from 500 to $1020 \mathrm{~ms}$. The unconditioned stimulus (US) is indicated by the vertical black line, ranging from 1000 to 1020 ms. (C) Histogram of the total number of CRs in \% observed in control subject (blue, $n=11$ ) and mefloquine users (red, $n=8 ;{ }^{*} p<0.05, t$ test). (D) The average percentages of CRs in each acquisition block is plotted for the control group (blue squares) and mefloquine group (red squares). Learning curves were used to fit both data sets $\left(R_{\text {control }}^{2}=0.98\right.$ and $\left.R_{\text {mefloquine }}^{2}=0.87\right)$.

within the blocks and as a whole. The eight blocks were preceded by the first block, called block 0 , during which participants were presented tone-only trials. In this block, we confirmed that the participants did not yet learned the ability to make a conditioned eye-blink response.

\section{STATISTICAL ANALYSES}

With regard to the performance experiments, all comparisons were done with paired, two-tailed $t$ test. For the learning experiments (i.e., eye-blink conditioning), we used the unpaired, two-tailed $t$ test. Furthermore, we fitted this learning data set with the following learning curve: the exponential function $y=a-a \cdot \exp ^{-x / b}$, where $y$ is the percentage of CRs, $x$ the block number, and $a$ and $b$ are the learning coefficients ( $a$ represents learning capacity and $b$ learning speed) of the model. The goodness of fit was indicated by $R^{2}$ values. All mean values were accompanied by standard error of the mean (SEM) unless stated otherwise.

\section{RESULTS}

In the study period of July 2009 to April 2010, 28 individuals were included. Nine participants volunteered for the performance experiments and 19 for the motor learning experiments (8 used mefloquine; 11 individuals served as control participants [no mefloquine use]). Table 1 summarizes the general characteristics of the individuals participating in the performance and motor learning experiments. Six participants reported adverse events after the intake of mefloquine (see Table 1 ).

\section{PERFORMANCE OF VOLUNTARY MOTOR TIMING, PERCEPTUAL TIMING, AND REFLEX TIMING IS NOT AFFECTED IN MEFLOQUINE USERS}

To find out whether mefloquine leads in humans to deficits in olivocerebellar related performances, we tested our participants before and after the intake of mefloquine (i.e., off and on medication), using specific tasks in which the IO is thought to be involved.

Voluntary motor timing was assessed by a dart throwing task. Throwing imprecision can be divided in a vertical and horizontal component. Imprecision in release timing or throwing speed is more reflected in the vertical deviation than in the horizontal deviation to the target (Figure 1A). Our participants revealed a significant larger vertical deviation than horizontal deviation under both conditions (Figure 1C, meflo: $p=0.01$, no meflo: $p=0.01, t$ test), indicating the more complex control of the vertical component over the horizontal component of the throw. The vertical deviation as well as the horizontal deviation was not affected by the use of mefloquine (Figure 1C, $p=0.47$ and $p=0.73$ respectively, $n=9, t$ test). In order to correct for non-specific inter-trial variability, we normalized the vertical deviation by the total deviation of each throw. These normalized vertical deviations did not reveal a significant difference (Figure 1D, $p=0.45, n=9, t$ test). Neither did the normalized variation in the vertical deviation, which is an indicator for vertical throwing precision (Figure 1E, $p=0.34, n=9, t$ test).

Since the IO has been suggested to play a role in the perception of complex rhythms (Xu et al., 2006), we investigated whether a rhythm perception task in mefloquine users would result in reduced ability to distinguish between rhythms (Figure 2A). No significant differences were found with respect to the number of errors made per perturbation between the two conditions (Figure 2B). The $25 \mathrm{~ms}$ perturbation yielded the largest difference, although not significant $(p=0.25, n=9, t$ test $)$.

The effect of mefloquine on an involuntary motor performance task was investigated by studying the reflex blink (Figure 3A). Reflex blinks obtained before and after the intake of mefloquine were analyzed kinetically. The onset, the peak time velocity and the peak time amplitude did not reveal a significant difference between participants "off" mefloquine compared to "on" mefloquine (Figure 3B, $p=0.78, n=9, t$ test). The precision in timing of the eye-blink was investigated by testing the standard deviation of these parameters. Although, the standard deviations were all larger when the participants were under the influence of mefloquine, they were not significantly larger (Figure 3C, $p=0.59, n=9, t$ test). 
In all performance tasks the variation was more closely examined with the coefficient of variation (CV). The resulting CVs were not significantly different either (unpublished observations). Taken together, these results show that mefloquine has no influence on these three different IO-related performance tasks.

\section{EYE-BLINK CONDITIONING IS AFFECTED IN MEFLOQUINE USERS}

To investigate whether the use of mefloquine leads to motor learning deficits in humans, we tested mefloquine users and control participants (i.e., no mefloquine use) using an eye-blink conditioning task (Figure 4A).

Compared to the control participants, mefloquine users showed a significant lower number CRs that were acquired during training and after training (Figures 4B,C, $p=0.02$, control participants: $n=11$ and mefloquine users: $n=8, t$ test). The percentage of CRs was on average $74.0 \pm 4.7 \%$ in the control group and $46.8 \pm 11.0 \%$ in the group of mefloquine users. The learning curves of the mefloquine group and the control group are plotted in Figure 4D. Before the task started, it was confirmed that volunteers did not respond to the tone and did respond to the US with an UR. Therefore, in block 0 no conditioned blinking has been observed. In blocks 1, 2, 4,5 , and 6 the number of CRs was significantly lower in the group of mefloquine users compared to the control group (respectively $p=0.03,0.01,0.01,0.04$, and $0.03, t$ test), whereas blocks 3,7 , and 8 did not reveal significantly difference (respectively $p=0.14,0.14$, and $0.08, t$ test). Curve fitting the data of both groups resulted in well-associated learning curves $\left(R_{\text {control }}^{2}=0.98, p<0.01\right.$ and $R_{\text {mefloquine }}^{2}=0.87, p<0.01$ ). The fitted learning curve generated two learning coefficients: $a$ and $b$. The learning coefficient $a$ represents learning capacity, whereas the learning coefficient $b$ represents learning speed. The coefficients $a$ and $b$ of the learning curves were both significantly different between the control group and the group of mefloquine users (control: $a=84.7 \pm 0.7$ and $b=1.53 \pm 0.05$ vs mefloquine: $a=70.8 \pm 7.2$ and $b=3.96 \pm 0.71$, both $p<0.05, t$ test). Mefloquine users learned this task 2.6 times slower than the participants that did not use mefloquine and their learning capacity was also reduced by $16 \%$ compared to the non-users. The average onset latency of the CRs was similar in the mefloquine group and control group (control: $877 \pm 14.8 \mathrm{~ms}$ vs mefloquine: $906 \pm 16.6 \mathrm{~ms}$, $p=0.23$, $t$ test). UR onset across groups did not differ either (control: $1062 \pm 6.1 \mathrm{~ms}$ vs mefloquine: $1075 \pm 4.5 \mathrm{~ms}, p=0.13, t$ test), excluding that possible deficits in reflex pathways can contribute to the observed reduced motor learning. Conclusively, these data show that the use of mefloquine affects motor learning.

\section{DISCUSSION}

In this study we investigated the possibility that mefloquine induces deficits in olivocerebellar related behaviors in young and healthy volunteers. We show that mefloquine has no effect on dart throwing, rhythm perception and reflex blinking, but has an effect on the conditioning of eye-blink responses to a tone (associative learning). In this learningdependent motor task, mefloquine users were impaired in their learning speed as well as in their learning capacity. Mefloquine reduced their learning speed by 2.6 times and their learning capacity by $16 \%$.

Animal studies in which mefloquine was injected in the IO and studies on Cx36-deficient mice have shown comparable motor learning problems (Frisch et al., 2005; Van Der Giessen et al., 2008).
The training process in these animals was slowed down substantially, but they revealed no impaired general motor performance (Kistler et al., 2002; Van Der Giessen et al., 2008) similar to our findings in humans. The lack of effect of mefloquine on general performance is most likely due to the specific function of $\mathrm{Cx} 36$ within the IO. Blocking Cx36 by mefloquine does not affect the performance, it makes the performance only unadjustable. In order to affect these performances other mechanisms within the IO need to be altered (Rondi-Reig et al., 1997; Welsh, 1998).

With regard to our experimental design, the question arises whether a single dose of mefloquine is capable of altering brain functions. Mefloquine has no problem crossing the blood-brain barrier (Baudry et al., 1997) and there is evidence that mefloquine can accumulate in the brain (Barraud de Lagerie et al., 2004). This is, for instance, supported by the observation of a higher risk of neuropsychiatric adverse events in the first days after first mefloquine intake (Schlagenhauf et al., 1996, 2003; van Riemsdijk et al., 2002), suggesting a direct effect of mefloquine on the brain. Some of these neuropsychiatric adverse events were also observed in our mefloquine using participants (Table 1). Furthermore, the reported $\mathrm{IC}_{50}$ of mefloquine for Cx36 is $0.3 \mu \mathrm{M}$ (Cruikshank et al., 2004) and this is much smaller than the mefloquine blood level concentration achieved with one dosage of $250 \mathrm{mg}$ mefloquine (Pennie et al., 1993), indicating that the level of mefloquine in the brain is high enough to alter brain functions.

Of course, one could argue that the altered brain function associated with mefloquine might be caused by mechanisms other than interference with Cx36 gap junction coupling. However, the $\mathrm{IC}_{50}$ values for mefloquine inhibiting ATP-sensitive potassium channels $\left(\mathrm{IC}_{50}=3 \mu \mathrm{M}\right)$, L-type calcium channels $\left(\mathrm{IC}_{50} \approx 10 \mu \mathrm{M}\right)$, delayed rectifier channels $\left(\mathrm{IC}_{50}=1 \mu \mathrm{M}\right)$, and volume- $\left(\mathrm{IC}_{50}=1 \mu \mathrm{M}\right)$ and calcium-activated chloride channels $\left(\mathrm{IC}_{50}=3 \mu \mathrm{M}\right)$ are all higher than those required for $\mathrm{Cx} 36$ blockade (Coker et al., 2000; Gribble et al., 2000; Maertens et al., 2000; Kang et al., 2001). So far, Cx36 gap junctions are the most mefloquine-sensitive molecules in the brain and the mefloquine blocking effect in the IO will lead to motor learning deficit (Van Der Giessen et al., 2008).

Finally, one could also suggest that the present findings might be explained by a confounding involvement of other Cx36 containing brain areas apart from the IO. Despite the fact that for all the tasks used in this study the involvement of the IO is necessary (RondiReig et al., 1997; Xu et al., 2006; Van Der Giessen et al., 2008), we cannot directly exclude a possible role of other Cx36 containing brain areas. It is, though, noteworthy that an altered attention due to mefloquine might have affected the dart throwing and the rhythm perception task; it cannot explain the results on eye-blink and eyeblink conditioning tasks, because not being aware of the stimuli does not prevent eye blinking or eye-blink conditioning (Smith et al., 2005). Thus, the most likely explanation for our results is the selective blocking of Cx36 gap junctions in the IO.

The demonstration that mefloquine, a marketed anti-malarial drug, imposes a deficit in motor learning capabilities in man might come as a surprise in the field of adverse events of malaria prophylaxis and treatment. Although this adverse effect is not defined on direct clinical grounds (i.e., people do not report the adverse effect reduced motor learning as a result of mefloquine usage), it can have 
clinical relevance. For example, the use of mefloquine may limit the speed and capacity to rehabilitate motor functions after traumatic injuries. Moreover, knowledge of this effect is also relevant for civil and military organizations that detach people to malaria endemic regions where they have to rely heavily on fine-tuning their motor skills or learn new motor skills. Therefore, this adverse effect should be further investigated and recognized by clinicians.

\section{REFERENCES}

Barraud de Lagerie, S., Comets, E., Gautrand, C., Fernandez, C., Auchere, D., Singlas, E., Mentre, F., and Gimenez, F. (2004). Cerebral uptake of mefloquine enantiomers with and without the P-gp inhibitor elacridar (GF1210918) in mice. Br. J. Pharmacol. 141, 1214-1222.

Baudry, S., Pham, Y. T., Baune, B., Vidrequin, S., Crevoisier, C., Gimenez, F., and Farinotti, R. (1997). Stereoselective passage of mefloquine through the blood-brain barrier in the rat. J. Pharm. Pharmacol. 49, 1086-1090.

Coker, S. J., Batey, A. J., Lightbown, I. D., Diaz, M. E., and Eisner, D. A. (2000). Effects of mefloquine on cardiac contractility and electrical activity in vivo, in isolated cardiac preparations, and in single ventricular myocytes. $\mathrm{Br}$. J. Pharmacol. 129, 323-330.

Condorelli, D. F., Belluardo, N., TrovatoSalinaro, A., and Mudo, G. (2000). Expression of Cx36 in mammalian neurons. Brain Res. Brain Res. Rev. 32, 72-85.

Condorelli, D. F., Parenti, R., Spinella, F., Trovato Salinaro, A., Belluardo, N., Cardile, V., and Cicirata, F. (1998). Cloning of a new gap junction gene (Cx36) highly expressed in mammalian brain neurons. Eur. J. Neurosci. 10, 1202-1208.

Crevoisier, C., Handschin, J., Barre, J., Roumenov, D., and Kleinbloesem, C. (1997). Food increases the bioavailability of mefloquine. Eur. J. Clin. Pharmacol. 53, 135-139.

Croft, A. M., and World, M. J. (1996). Neuropsychiatric reactions with mefloquine chemoprophylaxis. Lancet $347,326$.

Cruikshank, S. J., Hopperstad, M., Younger, M., Connors, B. W., Spray, D. C., and Srinivas, M. (2004). Potent block of Cx36 and Cx50 gap junction channels by mefloquine. Proc. Natl. Acad. Sci. U.S.A. 101, 12364-12369.

De Zeeuw, C. I., Hertzberg, E. L., and Mugnaini, E. (1995). The dendritic lamellar body: a new neuronal organelle putatively associated with dendrodendritic gap junctions. $J$. Neurosci. 15, 1587-1604.

Dow, G. S., Hudson, T. H., Vahey, M., and Koenig, M. L. (2003). The acute neurotoxicity of mefloquine may be mediated through a disruption of calcium homeostasis and ER function in vitro. Malar. J. 2, 14.

Even, C., Friedman, S., and Lanouar, K. (2001). Bipolar disorder after mefloquine treatment. JPsychiatry Neurosci 26, 252-253.

Frisch, C., De Souza-Silva, M. A., Sohl, G., Guldenagel, M., Willecke, K., Huston, J. P., and Dere, E. (2005). Stimulus complexity dependent memory impairment and changes in motor performance after deletion of the neuronal gap junction protein connexin 36 in mice. Behav. Brain Res. 157, 177-185.

Gormezano, I., Schneiderman, N., Deaux, E., and Fuentes, I. (1962). Nictitating membrane: classical conditioning and extinction in the albino rabbit. Science 138, 33-34.

Gribble, F. M., Davis, T. M., Higham, C.E., Clark, A., and Ashcroft, F. M. (2000). The antimalarial agent mefloquine inhibits ATP-sensitive K-channels. Br. J. Pharmacol. 131, 756-760.

Kang, J., Chen, X. L., Wang, L., and Rampe, D. (2001). Interactions of the antimalarial drug mefloquine with the human cardiac potassium channels KvLQT1/minK and HERG. J. Pharmacol. Exp. Ther. 299, 290-296.

Kistler, W. M., De Jeu, M. T., Elgersma, Y., Van Der Giessen, R. S., Hensbroek, R., Luo, C., Koekkoek, S. K., Hoogenraad, C. C., Hamers, F. P., Gueldenagel, M., Sohl, G., Willecke, K., and De Zeeuw, C. I. (2002). Analysis of Cx36 knockout does not support tenet that olivary gap junctions are required for complex spike synchronization and normal motor performance. Ann. N. Y. Acad. Sci. 978, 391-404.

Koekkoek, S. K., Den Ouden, W. L., Perry, G., Highstein, S. M., and De Zeeuw, C. I. (2002). Monitoring kinetic and frequency-domain properties of eyelid responses in mice with magnetic distance measurement technique. J. Neurophysiol. 88, 2124-2133.

Lim, L. Y., and Go, M. L. (1985). The anticholinesterase activity of mefloquine. Clin. Exp. Pharmacol. Physiol. 12, 527-531. K. (2008). Specificity of inferior
Liu, T., Xu, D., Ashe, J., and Bushara,

\section{ACKNOWLEDGMENTS}

We are grateful for the contribution of the participants. We thank the nurses of the Travel Clinic in Rotterdam for their assistance during the recruitment of the volunteers. We also acknowledge the help of Dr. A. Smit and J. Willems with the eye-blink experiments. This work was supported by the Netherlands Organization for Scientific research (ZonMw: grant 971.96.347).

olive response to stimulus timing. J. Neurophysiol. 100, 1557-1561.

Maertens, C., Wei, L., Droogmans, G., and Nilius, B. (2000). Inhibition of volume-regulated and calciumactivated chloride channels by the antimalarial mefloquine. J. Pharmacol. Exp. Ther. 295, 29-36.

Margineanu, D. G., and Klitgaard, H. (2006). The connexin 36 blockers quinine, quinidine and mefloquine inhibit cortical spreading depression in a rat neocortical slice model in vitro. Brain Res. Bull. 71, 23-28.

Medina, J.F., Nores, W. L., Ohyama, T., and Mauk, M. D. (2000). Mechanisms of cerebellar learning suggested by eyelid conditioning. Curr. Opin. Neurobiol. 10, 717-724.

Palmer, K. J., Holliday, S. M., and Brogden, R. N. (1993). Mefloquine. A review of its antimalarial activity, pharmacokinetic properties and therapeutic efficacy. Drugs 45, 430-475.

Pennie, R.A., Koren, G., and Crevoisier, C. (1993). Steady state pharmacokinetics of mefloquine in long-term travellers. Trans. R. Soc. Trop. Med. Hyg. 87, 459-462.

Piening, R. B., and Young, S. A. (1996). Mefloquine-induced psychosis. Ann. Emerg. Med. 27, 792-793.

Rondi-Reig, L., Delhaye-Bouchaud, N., Mariani, J., and Caston, J. (1997). Role of the inferior olivary complex in motor skills and motor learning in the adult rat. Neuroscience 77, 955-963.

Schlagenhauf, P., Steffen, R., Lobel, H., Johnson, R., Letz, R., Tschopp, A., Vranjes, N., Bergqvist, Y., Ericsson, O., Hellgren, U., Rombo, L., Mannino, S., Handschin, J., and Sturchler, D. (1996). Mefloquine tolerability during chemoprophylaxis: focus on adverse event assessments, stereochemistry and compliance. Trop. Med. Int. Health 1, 485-494.

Schlagenhauf, P., Tschopp, A., Johnson, R., Nothdurft, H. D., Beck, B., Schwartz, E., Herold, M., Krebs, B., Veit, O., Allwinn, R., and Steffen, R. (2003). Tolerability of malaria chemoprophylaxis in non-immune travellers to sub-Saharan Africa: multicentre, randomised, double blind, four arm study. BMJ 327, 1078.

Simpson, J. I., Wylie, D. R., and De Zeeuw, C. I. (1996). On climbing fiber signals and their consequence(s). Behav. Brain Sci. 19, 380-394.

Smeets, J. B., Frens, M. A., and Brenner, E. (2002). Throwing darts: timing is not the limiting factor. Exp. Brain Res. 144, 268-274.

Smit, A. E., van der Geest, J. N., Vellema, M., Koekkoek, S. K., Willemsen, R., Govaerts, L. C., Oostra, B. A., De Zeeuw, C. I., and VanderWerf, F. (2008). Savings and extinction of conditioned eyeblink responses in fragile X syndrome. Genes Brain Behav. 7 , 770-777.

Smith, C. N., Clark, R. E., Manns, J. R., and Squire, L. R. (2005). Acquisition of differential delay eyeblink classical conditioning is independent of awareness. Behav. Neurosci. 119, 78-86.

Sohl, G., Maxeiner, S., and Willecke, K. (2005). Expression and functions of neuronal gap junctions. Nat. Rev. Neurosci. 6, 191-200.

Strick, P. L., Dum, R. P., and Fiez, J. A. (2009). Cerebellum and nonmotor function. Annu. Rev. Neurosci. 32, 413-434.

Toovey, S. (2009). Mefloquine neurotoxicity: a literature review. Travel Med. Infect Dis. 7, 2-6.

Van Der Giessen, R. S., Koekkoek, S. K., van Dorp, S., De Gruijl, J. R., Cupido, A., Khosrovani, S., Dortland, B., Wellershaus, K., Degen, J., Deuchars, J., Fuchs, E. C., Monyer, H., Willecke, K., De Jeu, M. T., and De Zeeuw, C. I (2008). Role of olivary electrical coupling in cerebellar motor learning. Neuron 58, 599-612.

van Riemsdijk, M. M., Ditters, J. M., Sturkenboom, M. C., Tulen, J. H., Ligthelm, R. J., Overbosch, D., and Stricker,B.H.(2002). Neuropsychiatric events during prophylactic use of mefloquine before travelling. Eur. J. Clin. Pharmacol. 58, 441-445.

Weiss, S. M., Benwell, K., Cliffe, I. A., Gillespie, R. J., Knight,A. R., Lerpiniere, J., Misra, A., Pratt, R. M., Revell, D., Upton, R., and Dourish, C. T. (2003). Discovery of nonxanthine adenosine A2A receptor antagonists for the treatment of Parkinson's disease. Neurology 61, S101-S106.

Welsh, J. P. (1998). Systemic harmaline blocks associative and motor learning by the actions of the inferior olive. Eur. J. Neurosci. 10, 3307-3320. 
Wu, X., Nestrasil, I., Ashe, J., Tuite, P., and Bushara, K. (2010). Inferior olive response to passive tactile and visual stimulation with variable interstimulus intervals. Cerebellum. [epub ahead of print].

$\mathrm{Xu}, \mathrm{D}$., Liu, T., Ashe, J., and Bushara, K. O. (2006). Role of the olivo-cerebellar system in timing. J. Neurosci. 26, 5990-5995.
Conflict of Interest Statement: The authors declare that the research was conducted in the absence of any commercial or financial relationships that could be construed as a potential conflict of interest.

Received: 16 July 2010; accepted: 28 October 2010; published online: 19 November 2010.
Citation: van Essen TA, van der Giessen RS, Koekkoek SKE, VanderWerf F, De Zeeuw CI, van Genderen PJJ, Overbosch $D$ and de Jeu MTG (2010) Anti-malaria drug mefloquine induces motor learning deficits in humans. Front. Neurosci. 4:191. doi: 10.3389/fnins.2010.00191

This article was submitted to Frontiers in Neuropharmacology, a specialty of Frontiers in Neuroscience.
Copyright (C) 2010 van Essen, van der Giessen, Koekkoek, VanderWerf, De Zeeuw, van Genderen, Overbosch and de Jeu. This is an open-access article subject to an exclusive license agreement between the authors and the Frontiers Research Foundation, which permits unrestricted use, distribution, and reproduction in any medium, provided the original authors and source are credited. 